Cipango Cahiers d'études japonaises

$21 \mid 2014$

Nouveaux regards sur les arts de la scène japonais II

\title{
Du texte à la scène, le théâtre de marionnettes en
} mutation

Donner à voir Amida no munewari (1614) au XxI ${ }^{\mathrm{e}}$ siècle

From the Text to the Stage, Puppet Theatre in Mutation: Directing Amida no Munewari (1614) in the Twenty-First Century

Chloé Viatte

\section{(2) OpenEdition}

Journals

Édition électronique

URL : https://journals.openedition.org/cipango/2318

DOI : $10.4000 /$ cipango.2318

ISSN : 2260-7706

Éditeur

INALCO

Édition imprimée

Date de publication : 31 décembre 2014

ISSN : 1164-5857

Référence électronique

Chloé Viatte, «Du texte à la scène, le théâtre de marionnettes en mutation », Cipango [En ligne], 21 |

2014, mis en ligne le 08 septembre 2016, consulté le 30 juin 2021. URL : http://

journals.openedition.org/cipango/2318; DOI : https://doi.org/10.4000/cipango.2318

Cipango est mis à disposition selon les termes de la Licence Creative Commons Attribution - Pas d'Utilisation Commerciale 4.0 International. 


\title{
Du texte à la scène, le théâtre de marionnettes en mutation
}

\author{
Donner à voir Amida no munewari (1614) au XXI ${ }^{\mathrm{e}}$ siècle \\ From the Text to the Stage, Puppet Theatre \\ in Mutation: Directing Amida no Munewari \\ (1614) in the Twenty-First Century
}

Chloé ViatTe

Université de Niigata

Le 13 avril 2012, la troupe Saruhachi-za 猿八座 donnait avec succès dans l'enceinte du temple Tōkōji 東光寺 (à Shibata, dans le département de Niigata) sa toute première représentation d'Amida no munewari 阿弥陀胸割 (Amida au poitrail déchiré), l'une des pièces les plus anciennes de l'histoire du théâtre de marionnettes.

Nishihashi Hachirobee 西橋八郎兵衛 (né en 1948), qui vit dans la localité de Saruhachi sur l'île de Sado et qui dirige cette troupe, cherche en effet à redonner vie au théâtre de marionnettes dit de style ancien, que l'on appelle kojōruri 古 浄瑠璃. Il s'appuie pour cela sur la tradition du théâtre de marionnettes, connue sous le nom de bun.ya ningyō 文弥人形, le bun.ya étant à l'origine un style de chant initié par Okamoto Bun.ya, récitant de jōruri pendant l'ère d'Enpō (16731681) à Osaka. L'île de Sado est l'un des quatre sites où cet art est encore préservé et la troupe Saruhachi-za en renouvelle le répertoire. 
96 Cahiers d'études japonaises $n^{\circ} 21$

Pourquoi donc, en ce début du XXI ${ }^{\mathrm{e}}$ siècle, s'intéresser à une œuvre obscure du début du XVII ${ }^{\mathrm{e}}$ siècle ? Comment rendre la complexité d'une pièce aux différentes facettes et prendre en compte les mutations scénographiques qu'elle a connues au cours de l'histoire ? Sur quels partis pris donner à voir cette pièce à nouveau ? Cet article se propose de retracer les évolutions que révèlent les livrets successifs de cette œuvre afin d'éclairer les choix faits par le metteur en scène contemporain. Ce faisant, c'est aussi à une histoire de la transformation du théâtre de marionnettes au cours du XVII ${ }^{\mathrm{e}}$ siècle que nous convions le lecteur.

\section{Contexte historique : la marionnette et les arts de la scène au début du $\mathrm{XVII}^{\mathrm{e}}$ siècle}

Transportons-nous il y a quatre cents ans. La période d'Edo vient à peine de commencer. À l'été 1614, une troupe itinérante de montreurs de marionnettes se produit dans la ville de Kanazawa. La pièce commence par les mots qui suivent ${ }^{1}$ :

Eh bien, voilà : il était un lieu situé aux confins du pays de Tenjiku [l'Inde] où se trouvait un Bouddha miraculeux dit « Amida au poitrail déchiré » (Munewari Amida). Le cœur se brise au récit détaillé de l'origine de cette si célèbre statue de la triade bouddhique ${ }^{2} \ldots$

さても其後 天竺の傍らに 胸割阿弥陀とて 名仏三 尊おはします 由来を詳しく尋ねるに 諸事の哀れを留 めたり

1. Livret de la troupe Saruhachi-za, retranscription de Watanabe Hachitayū 渡部八太夫 (récitant de tama-sekkyō) et Nishihashi Hachirobee 西橋八郎兵衛 du 13 octobre 2011 à partir du texte disponible dans Kokubungaku kenkyu shiryōkan zōhō 国文学研究資 料館蔵報 (Publications de l'Institut National de Littérature japonaise), no ${ }^{\circ}$ 2, Tōkyō, mai 2010, http://www.nijl.ac.jp/pages/articles/200712/. «Edition typographiée dite ancienne 》 (kokatsujiban 古活字版) qui daterait des ères Keichō 慶長 ou Genna 元和, soit entre 1596 et 1624.

2. Amida sanzon 阿弥陀三尊, ensemble de trois statues représentant le bouddha Amida entouré de Kannon, bodhisattva de la compassion, et de Dai Seishi, bodhisattva de la sagesse. Cette triade vient lors du trépas accueillir le défunt qui a invoqué le nom d'Amida pour le conduire dans sa Terre pure, loin dans la direction du soleil couchant. 
En septembre de la même année, la même troupe joue la pièce à la capitale devant l'empereur retiré Go-Yōzei 後陽成 (1571-1617). Cette dernière représentation est évoquée dans les notes journalières d'un membre de la noblesse de cour et poète, Nishinotōin Tokiyoshi 西洞院時慶 (1552-1640), qui laisse une description précieuse de l'impression qu'elle lui laissa :

$21^{\mathrm{e}}$ jour du $9^{\mathrm{e}}$ mois. Il a plu. Je me suis rendu au palais de l'empereur retiré. Après le repas, j'ai assisté à la représentation d'une pièce intitulée Le déchirement de la poitrine d'Amida (Amida munewarikiri). Des montreurs de marionnettes de type ebisu-kaki ont été autorisés à jouer au palais. Ils ont déployé leur rideau dans le jardin du palais et joué cette pièce. C'était très remarquable.

九月廿一日、雨天、院参。飯後、阿弥陀胸割切卜云、 曲 习仕。戎舁ノ類ノ者、推参卜ソ、於御庭、緞子幕等 引趈シテ、有曲。奇意ノコト也 ${ }^{3}$

Un autre membre de la noblesse de cour, Yamashina Tokio 山科言緒 (15771620), mentionne brièvement la même représentation ${ }^{4}$ :

Pluie. Je me suis rendu au palais impérial. J'ai assisté à la représentation d'Amida munewari et d'autres pièces de marionnettes manipulées.

雨、院参、阿弥陀ムネワリ其外種々ノアヤツリアリ

En l'état actuel des recherches, on considère que ce sont les plus anciennes attestations de représentations du théâtre de marionnettes manipulées données au palais impérial. La cour était plus attachée en ce début de XVII ${ }^{\mathrm{e}}$ siècle à la majesté du théâtre nô qu'aux spectacles populaires de montreurs de marionnettes. Pour l'occasion, le récitant avait d'ailleurs reçu le titre particulier de jō 掾, que

3. Tokiyoshi-kyōki 時慶卿記, cité par ToRIgOE Bunzō 鳥越文蔵, UCHIYAMA Mikiko 内山美樹子, WATANABE Tamotsu 渡辺保 (dir.), Kabuki, bunraku - Jōruri no tanjō to kojōruri 歌舞伎 文楽一浄瑠璃の誕生と古浄瑠璃 (Kabuki, bunraku: naissance du jōruri et ancien jōruri), vol. 7, Tōkyō, Iwanami shoten 岩波書店, 1998, p. 41.

4. Tokio-kyōki 言緒卿記, cité dans NINGYŌ BUTAI-SHI KENKYŪKAI 人形舞台史研究 会 (dir.), Ningyō jōruri butai-shi 人形浄瑠璃舞台史 (Histoire de la mise en scène du théâtre de marionnettes), Tōkyō, Yagi shoten 八木書店, 1991, p. 12. 


\section{CIPANGO}

98 Cahiers d'études japonaises n ${ }^{\circ} 21$

Jean-Jacques Tschudin traduit par « sous-gouverneur » ${ }^{5}$, de la région de Kawachi. Sans ce titre purement honorifique attaché à une région et qui donnait un caractère officiel à sa troupe, un simple montreur de marionnettes n'aurait pu se produire devant une si noble assistance. La troupe donna aussi en complément de cette pièce des adaptations de trois pièces de nô : Kamo, Daibutsu kuyō et Takasago. Le nô occupait alors une place centrale chez les nobles et les guerriers de haut rang et son ombre planait sur toutes les conceptions des arts de la scène. Il restait la référence, comme en témoigne une note du journal du palais tenu en kana par les femmes au service de l'empereur Oyudono no ue no nikki 御湯殿上日記 (18 jour du premier mois 1590):

Des ebisu-kaki sont venus et ont dansé dans le jardin. [...] Ils étaient tous vraiment excellents, ils faisaient danser leurs marionnettes comme lors d'une véritable présentation de nô. Chacune des pièces était merveilleuse !

总びすかき参り候て、御か、りにてまふ。 [...]总びす かき、みなみな一たんとのちちおうずにて、ほんのの ふのごとくに、しまいらせて、一たん一たんおもしろき 事なり ${ }^{6}$

Le succès rencontré par les danses de marionnettes, appelées « nô de marionnettes », nō ningyō 能人形, ou plus tard 《nô manipulé », nō-ayatsuri 能操 $\eta$, atteste d'une certaine porosité, entre les genres théâtraux et du passage d'une scène à l'autre, des livrets et des techniques de représentation. Ces nō ningyō sont attestés dès 1556, et les montreurs de marionnettes appelés ebisu-kaki s'en étaient

5. Jean-Jacques Tschudin, Histoire du théâtre classique japonais, Toulouse, Anacharsis, 2011, p. 259.

6. Torigoe Bunzō 鳥越文蔵, Uchiyama Mikiko 内山美樹子, Watanabe Tamotsu 渡辺保 (dir.), op. cit., 1998, p. 33. 
fait une spécialité7. Comme le souligne Muroki Yatarō 室木弥太郎, la virtuosité de ces nô de marionnettes avait dû être assez impressionnante pour que l'empereur Go-Yōzei qui affectionnait les arts ait, sans doute en personne, invité au palais les meilleurs montreurs de marionnettes ebisu-kaki. Les dames de cour en avaient, semble-t-il, été ravies ${ }^{8}$.

Au milieu du XVI ${ }^{\mathrm{e}}$ siècle, le mot ebisu-kaki est le terme le plus usité pour désigner les marionnettistes itinérants. Ceux-ci avaient pour foyer l'actuel département de Hyōgo, c'est-à-dire la région qui se situe entre Osaka et Kōbe. Ils vivaient dans les alentours du sanctuaire de Nishinomiya 西宮神社 qui avait été dédié tout d'abord à la divinité Hiruko no mikoto 蛭子命 et fut identifié par la suite au dieu Ebisu 恵比寿 9 . Ils devinrent célèbres en parcourant le Japon. Attachés au sanctuaire de Nishinomiya dont ils distribuaient les amulettes, ils furent tout d'abord appelés nishinomiya-kaki. Ils donnaient des spectacles de petites poupées en tenant devant eux une petite scène constituée par une boîte sans socle qu'ils portaient suspendue à leur cou (c'est le sens du verbe kaku 舁sous la forme kaki).

Aujourd'hui même, une troupe du nom d'Ebisu-za, sise dans le département de Hyōgo, perpétue cette forme de théâtre de marionnettes. Jusqu'en 2012, elle ne se produisait que dans sa propre salle de théâtre, mais elle participe depuis à toutes sortes de festivals.

Allant de maison en maison comme des annonciateurs du bonheur et de la prospérité, ces artistes itinérants de jadis furent connus pour leur personnage du dieu Ebisu toujours représenté pêchant un gros poisson. Ebisu-kaki est devenu par la suite une appellation générique appliquée à d'autres spectacles de marionnettes. Ce n'est qu'au milieu du XVI ${ }^{\mathrm{e}}$ siècle que le Jöruri jünidan zōshi 浄瑠璃十二段

7. Le dictionnaire japonais-portugais de la fin du XVI ${ }^{\mathrm{e}}$ siècle (dans sa version traduite plus tard en français) mentionne sous leurs graphies anciennes les mots yebisu « marionnette », yebisu o mawasu « faire danser les marionnettes » ainsi que yebisu kaki ou yebisu mawashi « celui qui fait danser les marionnettes » (Léon PAGÉs, Dictionnaire japonais-français, Paris, Firmin Didot, 1868, p. 900).

8. Torigoe Bunzō 鳥越文蔵, Uchiyama Mikiko 内山美樹子, Watanabe Tamotsu 渡辺保 (dir.), op. cit., 1998, p. 35.

9. Hiruko no mikoto est le premier enfant qu'engendrèrent les deux divinités Izanagi et Izanami de la mythologie japonaise. Étant mal formé, il fut abandonné dans les eaux. 


\section{CIPANGO}

草子 (Les douze épisodes de l'histoire de demoiselle Jōruri) ${ }^{10}$, narré sans doute dès le $\mathrm{XV}^{\mathrm{e}}$ siècle, connut un succès tel que l'on se mit à désigner les spectacles de marionnettes par le terme de «poupées de jōruri ${ }^{11}$ (ningyō jōruri 人形浄 瑠璃). Le titre de ce récit apparaît pour la première fois dans les notes journalières du célèbre noble et lettré Sanjōnishi Sanetaka 三条西実隆 (1455-1537), Sanetaka-kōki 実隆公記, au $7^{\mathrm{e}}$ mois de l'an 1475. Il faut attendre 1531 pour la première mention, dans les notes journalières du moine et poète Sōchō 宗長 (1448-1532), d'une version explicitement chantée : « Ils furent priés de chanter jöruri $\gg^{12}$ (Jóruri o utawase 浄瑠璃をうたはせ). Enfin, c'est en 1587 que, dans les notes journalières de Yamashina Tokitsune 山科言経 (1543-1611), Tokitsune-kyōki 言経卿記, il est fait allusion à un accompagnement du récit par un shamisen, sorte de banjo à trois cordes qui venait d'être introduit au Japon via le royaume de Ryūkyū vers 1560 .

En 1614, nous sommes encore aux débuts de la vogue des marionnettes et la pièce Amida no munewari fait date par son thème, son écriture et sa composition. Nishinotōin Tokiyoshi 西洞院時慶 évoqué plus haut confie son trouble devant cet objet scénique. Il souligne notamment la nouveauté du spectacle qu'il lui a été donné de voir. La pièce étonne et la technique semble différente de celle des marionnettistes qu'il connaissait quand il parle encore dans son journal de marionnettes « de type » ebisu-kaki. Yamashina Tokio 山科言緒 de son côté ose le terme ayatsuri (manipulation [de marionnettes]). Ces témoignages laissent deviner ce qui a dû marquer les observateurs de l'époque, un nouveau genre était en train de voir le jour. Il ne s'agit plus de montreurs promenant leurs boîtes mais de véritables représentations d'un théâtre de poupées intégrées dans un espace scénique : le style ayatsuri jōruri (récitatif illustré par des marionnettes) était né,

10. Ce récit a été traduit du japonais par René SiefFert, Histoire de demoiselle Jōruri, Cergy, Publications orientaliste de France, 1994.

11. 《Jōruri no tanjō, Kojōruri » 浄瑠璃の誕生 古浄瑠璃 (La naissance du jōruri, le récitatif ancien), in ToRigoe Bunzō 鳥越文蔵, UchiYama Mikiko 内山美樹子, Watanabe Tamotsu 渡辺保 (dir.), op. cit., 1998, p. 17.

12. Sōchō nikki 宗長日記, $15^{\mathrm{e}}$ nuit de la $8^{\mathrm{e}}$ lune de la $4^{\mathrm{e}}$ année de Kyōroku. 
comme le souligne toujours Muroki Yatarō 室木弥太郎 ${ }^{13}$. Amida no munewari marque l'émergence d'une nouvelle forme de spectacle.

Cette pièce innovait et marqua les esprits. Il en est fait très clairement mention sur des représentations picturales telles que les fameux paravents de Funaki (vers 1615) attribués au célèbre peintre Iwasa Matabee 岩佐又兵衛 (1578-1650). Ces deux paravents de six panneaux chacun décrivent la capitale impériale du début du $\mathrm{XVII}^{\mathrm{e}}$ siècle, entre le château de Nijō-jō et le temple du Hōkōji. Plus de 2500 figures humaines s'y affairent. Le paravent de droite représente les alentours du Hōkōji et sur le deuxième panneau en partant de la gauche, le peintre a rendu le foisonnement de la ville basse (shimo-gyō 下京). Non loin du pont de la $5^{\mathrm{e}}$ avenue la foule se presse sur les bords de la Kamo, à Shijō kawaramachi 四条河原町, célèbre « quartier de la grève de la quatrième avenue », où se trouvaient toutes sortes de salles de spectacles, notamment de kabuki. Il n'est pas encore interdit aux femmes de réjouir les spectateurs avec leurs danses de kabuki. Non loin de ces spectacles, dans deux enclos pouvant accueillir chacun une vingtaine de spectateurs, deux troupes donnent des spectacles de marionnettes. Au-dessus de l'une des scènes est placée une apostille du titre de la pièce Yamanaka Tokiwa ayatsuri 山中と きはあやつり (Marionnettes de Yamanaka Tokiwa) ${ }^{14}$. Au-dessus de l'autre, on peut lire en kana Munewari ayatsuri むねわり あやつり (Marionnettes du Poitrail déchiré $)^{15}$. Si les proportions ont été gardées, les poupées doivent faire une trentaine de centimètres. L'espace de scène entre la haute rampe du proscenium et le rideau de fond est très étroit, les manipulateurs sont dissimulés derrière la frise avant - sans doute accroupis - et manœuvrent les poupées par les jambes. On peut estimer que la rampe devait faire plus d'un mètre, ce qui correspond à la

13. Torigoe Bunzō 鳥越文蔵, UChiYama Mikiko 内山美樹子, WatAnABe Tamotsu 渡辺保 (dir.), op. cit., 1998, p. 42.

14. Le drame de la mère de Yoshitsune, Tokiwa, qui voulant revoir son fils sera attaquée dans une auberge pour ses beaux vêtements et, préférant la mort à se retrouver nue, sera tuée par ces brigands. Yoshitsune apprendra plus tard ce crime et vengera sa mère.

15. Paire de paravents connue sous le nom de Funaki byōbu (Paravents de la famille Funaki). Elle appartient à la catégorie des rakuchū rakugai-zu byōbu 洛中洛外図屏風 (paravents décrivant la capitale et ses environs). Elle est conservée au musée National de Tōkyō. 
102 Cahiers d'études japonaises n²1

hauteur utilisée par la troupe de Bun.ya du département d'Ishikawa. Le spectacle est en cours, nous serions au milieu de la pièce. Côté jardin se tient la poupée représentant le personnage d'un seigneur du nom de Daiman, les deux petites poupées du côté cour doivent être Tenjū et son jeune frère Teirei qui viennent se vendre pour le salut de leurs parents.

Iwasa Matabee 岩佐又兵衛 semble avoir été dûment impressionné par ce spectacle, puisqu'une autre œuvre lui étant attribuée montre dans un vaste enclos une cinquantaine de spectateurs hommes, femmes, enfants, guerriers sabre au clair, moines, tous mêlés, qui assistent, assis cette fois, à la représentation de Munewari. L'artiste a choisi de représenter la scène finale. Une petite chapelle de bois abritant la statuette de la triade bouddhique Amida sanzon est posée côté cour sur le rebord d'une haute rampe recouverte de tissus bigarrés. Les enfants Tenju et Teirei semblent être assoupis au pied de la statue. Côté jardin, le seigneur coiffé de son couvre-chef à la chinoise et ses vassaux entrent en scène pour constater le miracle.

Mais prenons le temps de narrer l'intrigue de ce récit miraculeux.

\section{Le livret d'Amida no munewari ou le récit d'un miracle}

L'action se situe dans l'Inde que les Japonais appellent Tenjiku et qui est le berceau lointain du bouddhisme. Un riche seigneur possède sept trésors qui le mèneront à sa perte. L'un d'eux est en effet un arbre merveilleux, un pin du nom de Otowa qui permet de rajeunir sans fin. Ne craignant plus la mort, ce seigneur comme son épouse se désintéressent de leur salut, se détachent du bouddhisme, proposent de brûler les temples et de se conduire sans morale ni vertu. Le Bouddha, ne pouvant tolérer de tels agissements, décide d'y mettre fin. Après d'épiques combats mettant en scène toutes sortes de démons, l'impie est finalement vaincu et le couple mis à mort (l'homme et la femme trépassent dans d'atroces souffrances, brûlés de l'intérieur par du plomb fondu).

Bouddha choisit d'épargner leurs deux enfants innocents. Orphelins et ruinés, les petits errent et mendient. Désireux avant tout d'ériger un temple pour le salut de leurs parents, ils décident de se vendre comme esclaves.

Personne ne voulant d'eux, ils s'en vont prier dans un temple où Amida leur apparaît en rêve et leur conseille de se rendre chez un lointain seigneur du nom de 
Daiman. Son fils est victime d'une malédiction : la mort lui est promise, sauf si le foie d'une fille née exactement à la même heure, le même jour du même mois de la même année que lui, lui est prodigué comme remède. L'ainnée, Tenju, remplit tous ces critères et accepte de se sacrifier à la condition qu'un temple, un autel et la triade d'Amida soient érigés pour le salut de ses parents et que son frère soit adopté. L'accord est conclu. L'heure du sacrifice arrive : le foie de Tenju est arraché et Matsuwaka, le fils agonisant du seigneur, guérit aussitôt. Mais au moment d'aller se recueillir auprès du corps de la fillette, on constate qu'elle a disparu. Elle est retrouvée endormie près de son frère dans le temple. La statue d'Amida est ensanglantée car il s'est offert pour sauver cette âme pure.

Donald Keene a évoqué la possibilité d'une influence chrétienne dans ce sacrifice du Bouddha pour la jeune enfant, mais le mi-gawari, ou «sacrifice de soi pour autrui » est très fréquent dans la religion populaire ${ }^{16}$. Plus encore que l'originalité de la thématique, on peut penser avec Muroki Yatarō 室木弥太郎 que c'est l'artifice du karakuri, la mécanique de scène permettant de faire saigner la statue en pleine représentation, qui a dû marquer les foules.

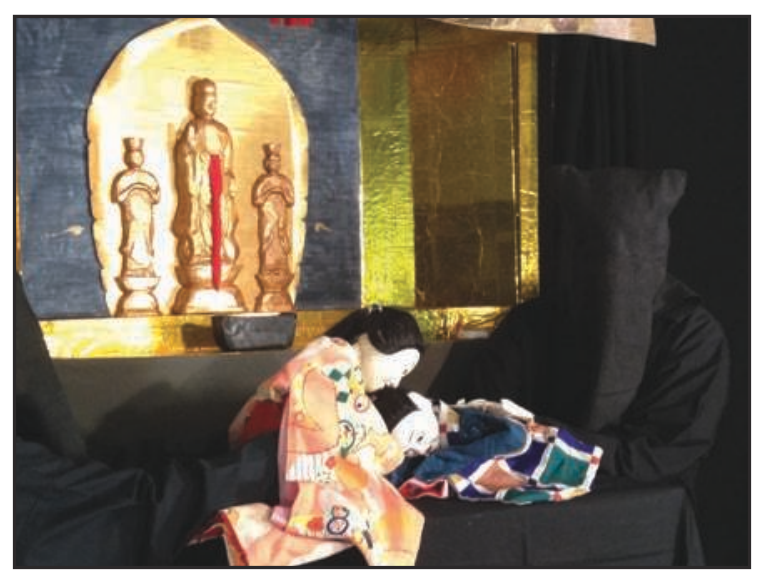

FIGURE 1.

Le miracle de la statue d'Amida ensanglantée. Spectacle de la troupe Saruhachi-za du 13 avril 2012. Source : cliché de Chloé Viatte

16. Donald Keene, Bunraku: The Art of the Japanese Puppet Theatre, Tōkyō, Kōdansha International Ltd, 1965. 
La rhétorique, on le voit, est éminemment bouddhique et le message édifiant qu'elle suggère incite l'audience à la piété filiale, à l'humilité et au sacrifice de soi si elle veut être sauvée et bénéficier des grâces d'un Bouddha qui peut apparaître courroucé, implacable ou bienveillant. Plus encore, et c'est un trait majeur des pièces du jöruri ancien, cette histoire a pour trame et personnage central une statue bouddhique dont elle vante les effets salvifiques. Ce que nous imaginerions aujourd'hui donné dans un lieu de fête et de spectacle était jadis joué dans les temples bouddhiques, et de nombreuses pièces anciennes avaient pour objectif premier de narrer les origines et la puissance des trésors qu'ils abritaient. Ainsi, la pièce Karukaya かるかや décrit notamment l'origine de deux bodhisattvas Jizō enchâssés au temple du Zenkōji ; les premières versions de Sanshō daȳu 山 椒大夫 (connu en France sous le nom de L'Intendant Sanshö, mis en scène par Mizoguchi Kenji) racontent le pouvoir d'une effigie de Jizō ; Aigo no Waka あ いごの若 nous narre les origines du dieu Sannōdai-gongen du temple Hiyoshi daisha ; le personnage principal du Kōchi Hōin go denki 弘知法印御伝記 est le moine Kōchi 弘知 qui, suite à une longue ascèse, est devenu Bouddha en corps (sokushin-butsu 即身仏). La momie de ce personnage historique est la plus ancienne de l'archipel, elle est vénérée de nos jours encore au Mont Yahiko. La liste de ces pièces hagiographiques serait longue. L'aspect divertissant était étroitement conjugué à des aspects religieux et moraux. Il permettait aux temples qui accueillaient ces pièces de faire la promotion de leur enseignement, de leur prestigieuse formation (engi), ainsi que de leurs trésors. La pièce d'Amida no munewari est d'ailleurs souvent classée dans le répertoire du sekkyō-bushi 説経節, appelé aussi sekkyō, genre de littérature orale issue de la prédication bouddhiste pratiquée en public par des moines errants. Le sekkyō d'inspiration religieuse est plus ancien que le jöruri qui tire, lui, ses origines de la plus ancienne des adaptations littéraires dérivées du récit épique narrant la grandeur et la chute du clan des Taira, le Heike monogatari.

À une époque où la notion d'auteur n'a guère d'importance, le livret n'est pas signé. Il aurait été écrit par une femme du nom de Rokuji Namuemon 六字 南無右衛門 (dates non connues). Son nom est constitué du mot rokuji (les six caractères) de la formule d'invocation na-mu-a-mi-da-butsu 南無阿弥陀仏. Il est suivi du mot namu qui est le premier terme de cette formule que l'on répète sans cesse dans les écoles de la Terre pure. Deux siècles plus tard, un érudit d'Edo, 
Saitō Gesshin 斎藤月岑 (1804-1878) écrit dans un traité intitulé Hyakugi jutsuryaku 百戯述略 (Bref exposé de cent jeux) :

Pendant l'ère Kan.ei [1624-43], la récitante Rokuji Namuemon contait autant du sekkyō que des histoires bouddhiques et faisait pleurer son public ${ }^{17}$.

Le succès lui aurait particulièrement souri alors qu'elle exerçait sur les rives de la Kamo à Kyōto. C'est l'époque où les récitants commencent à attirer les regards. Certains sont adulés et les rares femmes récitantes étaient particulièrement appréciées. Muroki Yatarō 室木弥太郎 y voit même l'un des ressorts du succès du genre du ayatsuri jöruri ${ }^{18}$. On attribue aussi à cette artiste le livret de Yashima (vers 1639), célèbre bataille entre les Taira et les Minamoto et celui de Soga, une histoire de vengeance qu'elle aurait adapté des pièces chantées du nô.

L'interdiction faite aux femmes dès 1629 d'apparaître sur scène aurait finalement mis un terme à sa carrière, mais elle eut des disciples et fonda un style de récitatif auquel on donna son nom, namuemon-bushi 南無右衛門節.

Dans Amida no munewari, les protagonistes errent, mendient et font un très long périple (michiyuki) comme dans les classiques du sekkyō. Sur ce point, cette pièce peut être rapprochée des pérégrinations des protagonistes des livrets Sanshō dayū ou encore de Karukaya évoqués plus haut, où un enfant recherche désespérément son père et subit de très douloureuses épreuves qui ne pouvaient que faire pleurer l'assistance. On pourrait s'étonner que de jeunes enfants soient ainsi appelés à parcourir l'Inde du Nord, traverser l'Everest, arriver en Chine avant de retourner sur leurs pas. Ce serait oublier que dans la littérature du Japon ancien depuis Heian, les itinéraires sont moins géographiques qu'allégoriques. Et cette pièce d'Amida no munewari ne déroge pas à la règle littéraire. L'errance symbolique des personnages est ponctuée de toponymes, certes exotiques et pitto-

17. MuRoki Yatarō 室木弥太郎, Katarimono (mai, sekkyō, kojōruri) no kenkyū 語り 物 (舞 説経 古浄瑠璃) の研究 (Études du récit [danse, sekkyō, jōruri ancien]), Tōkyō, Kazama shobō 風間書房, 1970, p. 24.

18. Torigoe Bunzō 鳥越文蔵, Uchiyama Mikiko 内山美樹子, Watanabe Tamotsu 渡辺保 (dir.), op. cit., 1998, p. 49. 
resques, mais retenus surtout pour leur valeur mélodique et métaphorique. Leur itinéraire marque et souligne le flux temporel autant qu'il suggère la détresse de ces êtres perdus sur la carte de la géographie bouddhique. Parcours initiatique et entendu comme tel. Ainsi, Amida leur apparaît en songe aux alentours de Bénarès (Hanarai-koku, Varanasi), moins pour les charmes de la ville que par ce qu'il s'agit de signifier l'un des quatre lieux saints du bouddhisme où le Bouddha historique fit son premier sermon. Après cette révélation, les enfants passent par la rivière Kikusui 菊水 ${ }^{19}$ (de l'autre côté de l'Everest) avant de retourner en Inde au bourg de Kō-yume, site imaginaire, où réside Daiman. Ce trajet qui fait fi des difficultés immenses que représenterait le passage de l'Everest pour ces deux enfants est bien sûr aberrant d'un point de vue géographique, mais il permet de faire passer aux protagonistes une propitiatoire rivière de longue vie, avant de les mener symboliquement au village du « rêve », ou plutôt au topos de « l'illusion », concept cher au bouddhisme.

Reste que leur voyage est pathétique, et le ton élégiaque, naki-bushi 泣き節, est justement la caractéristique historique du style bun.ya jadis tant prisé et qui a été préservé sur l'île de Sado. Jacqueline Pigeot, dans son ouvrage de référence sur le michiyuki-bun, analyse notamment l'influence du bouddhisme sur la littérature et l'émergence des honji-mono, « œuvres qui relatent la carrière d'un dieu ou d'un Bouddha avant son accession à ce rang, en tant qu'être de ce monde ${ }^{20}$. Les souffrances sont la condition de la salvation et de l'élévation au rang de dieu ou de Boddhisattva. Dans Amida no munewari, les pérégrinations des personnages sont des expériences pathétiques et initiatrices. L'impermanence des choses, mujō, réduit les orphelins à l'errance, ils expient les crimes de leurs parents, leur dignité dans la souffrance attire donc sur eux la miséricorde d'Amida et conditionne leur délivrance. Les émotions profanes d'affliction aware que les spectateurs ressentent au récit de ces souffrances servent le sentiment religieux. Leur voyage est à l'image

19. Rivière dont le nom s'écrit aussi 鞠水, et qui prend sa source dans les monts Min de la province du Henan en Chine avant de devenir un affluent de la Baishui (白水江－白河), elle-même affluente du Yang Yangzi Jiang. Ses eaux sont réputées pour leur saveur et une légende voudrait qu'elles garantissent l'éternelle jeunesse à ceux qui en boivent.

20. Jacqueline Pigeot, Michiyuki-bun, poétique de l'itinéraire dans la littérature du Japon ancien, Paris, Maisonneuve et Larose, 1982, p. 313. 
de la précarité de la vie. Le meilleur bâton de pèlerin en ce bas monde est la foi en Amida, nous rappelle la pièce.

\section{Les évolutions du livret, une œuvre inclassable?}

Si un célèbre récitant comme Tenma Hachitayū 天満八太夫 (-1704) n'a pas hésité à mettre ce livret à son répertoire dans la catégorie du sekkyō, Amida au poitrail déchiré fut aussi souvent classé en «jōruri ancien », kojöruri, et ce dès l'ère Keian (1648-1654). Cette œuvre appartient au sekkyō, par sa thématique bouddhique et les aventures de ses personnages principaux. Mais le style et les tournures tranchent. Un spécialiste comme Muroki Yatarō 室木弥太郎 voit dans le texte de cette œuvre des caractéristiques qui dérogent aux canons stylistiques du sekkyō de Kyōto. Il cite notamment les terminaisons en -teni, sans pouvoir y trouver non plus une filiation avec le style tōkaidō-bushi emblématique du jōruri ${ }^{21}$. Par ailleurs, Yokoyama Shigeru 横山重 (1896-1980) argumente ainsi :

L'œuvre intitulée Amida no munewari ne serait-elle pas un livret original seihon de jöruri ancien? Je ne pense pas qu'elle relève du sekkyō. On ne trouve presque aucune des tournures stylistiques caractéristiques du sekkyō. C'est la raison pour laquelle elle a été cataloguée comme le $31^{\mathrm{c}}$ livret du jöruri ancien ${ }^{22}$.

Le texte est écrit sans découpage, mais les incipits des scènes ${ }^{23}$ permettent de dénombrer six tableaux. Alors qu'il est de coutume que les personnages sur lesquels s'est achevée une scène reviennent à la suivante, le principe n'est pas suivi ici, ce qui constitue une caractéristique de ce texte passionnant à plus d'un titre. De fait, la thématique de cette œuvre semble relever du sekkyō mais avoir été adaptée en jôruri. La stratification sociale de la société d'Edo, qui se durcit après la fin de la période des provinces en guerre, va à l'encontre des groupes d'artistes et de moines

21. Muroki Yatarō 室木弥太郎, op. cit., 1970, p. 24.

22. Ibid., p. 253.

23. Comme les locutions sate (eh bien), satemo さても (or donc), satemo sono nochi 扱て も其の後 (et ensuite). 
ambulants et profite au contraire à une nouvelle génération de saltimbanques moins imprégnés des traditions et plus libres dans leur approche de la performance. Car si Amida no munewari est cet objet littéraire complexe, il existait un Amida-honji あみだ本地 (les origines d'Amida), histoire qui lui est antérieure et qui, elle, appartient bien aux traditions du sekkyo ${ }^{24}$. Cette œuvre est peut-être l'un des premiers fruits de cette évolution des arts de la scène de l'époque, jouée sur un mode nouveau par une troupe où le récitant aurait librement innové sur une trame de type sekkyo.

\section{Un tournant dans l'écriture? La construction de la pièce}

Chaque tableau est mis sous le signe d'une couleur particulière. Le fantastique, le tragique et le dramatique se succèdent pour rythmer une représentation conçue sur l'alternance de ces catégories.

Le premier tableau est un défi pour le metteur en scène, mais dut faire la joie des spectateurs grâce à ses changements de scène fréquents, ses nombreuses apparitions miraculeuses, ses combats épiques et son sidérant final du supplice des parents. Mené tambour battant, il s'ouvre au Bengale oriental où réside le seigneur impie, puis se déplace au cour de l'Inde au Madhya Pradesh sur le Griddhraj Parvat, « le Pic sacré de l'aigle », célèbre au Japon sous le nom de Ryōjusen 霊熟 山. Ayant décidé de punir le seigneur Kanshi Byōe かんし兵衛 qui, riche de trésors magiques, bafoue par orgueil les lois bouddhiques, Shakyamuni convoque le Roi Démon du sixième ciel, Dairokuten no maō 第六天の魔王 ${ }^{25}$, et lui demande de se rendre chez le seigneur sacrilège pour l'anéantir. Mais ce dernier possède deux épées magiques capables de repousser les démons. Battu, Maō retourne sur le Mont sacré pour expliquer qu'il a échoué dans sa mission punitive. Shakyamuni enjoint à 98000 dieux malfaisants de s'abattre sur la résidence de l'impie, sans

24. Muroki Yatarō 室木弥太郎, op. cit., 1970, p. 255.

25. Le « Roi Démon du sixième ciel » est le terrible esprit du mal qui règne sur le monde du désir et empêche les êtres de se libérer de lui. Le bouddha Shakyamuni repoussa ses assauts avant d'atteindre l'éveil parfait. 
plus de succès. Il décide alors de demander à ses disciples de se rendre aux enfers pour solliciter de l'aide. Shōki 鍾馗, le conjurateur de démons ${ }^{26}$, arrive finalement à bout des épées magiques. Afin de punir l'impiété de ce seigneur sans vergogne, ses trésors sont anéantis, les villageois tués par milliers et les coupables subissent une mort atroce.

Multiplicité de lieux, déplacements incessants, personnages par milliers, la mise en scène s'avère redoutable. Cette partie semble montrer que le texte est antérieur à un projet scénique et qu'il n'a pas été formaté explicitement pour une représentation.

Tout au contraire du premier tableau, le second est empreint de tristesse (aware). Les héros sont les deux enfants du feu seigneur Kanshi Byōe かんし兵 衛, la jeune Tenju 天寿 et son frère Teirei ていれい, dont le calvaire est décrit. Le thème n'est pas rare dans le théâtre de poupées. Donald Keene soutient d'ailleurs que le relais de la marionnette a justement permis le développement de pièces où les protagonistes sont de jeunes enfants. Car si leurs malheurs sont plus prompts à émouvoir les spectateurs, il est plus aisé de rendre avec justesse ces scènes avec la voix d'un chanteur aguerri appuyant le jeu d'une marionnette que de demander à de vrais enfants d'interpréter ces rôles difficiles nécessitant la lecture de sûtras ou la composition de poème. Désemparés de ne trouver preneur alors qu'ils ont résolu de se vendre, les protagonistes trouvent refuge dans un temple et prient Amida « Namu (sai) hōkokuraku ». Et de chagrin, avant de s'endormir, la jeune Tenju compose un poème :

Asakahono itushika hanawa chirihatete hanikihe nokoru tsuyu somono uki

朝顔のいつしか花は散り果て々 葉に消へ残る 露 そもの憂き

Que nous traduirons ainsi :

26. Shōki 鍾道, Zhong Kui, exorciste légendaire de la tradition chinoise, est repris dans l'imaginaire japonais. Érudit barbu à la laideur effrayante, il aurait rejoint après sa mort le Roi des Enfers. Selon les traditions il serait capable de repousser les maladies et les mauvais sorts, et de combattre les démons. 
Les fleurs de l'ipomée, en un matin fleurissent, flétrissent. Sur les feuilles reste, délaissée, si triste la rosée.

Mais Amida leur apparaît en songe et leur révèle où se rendre. L'errance va pouvoir prendre fin. Ce poème est donc passionnant à plus d'un titre. On s'étonne tout d'abord de sa présence au milieu d'un livret scénique, puis on constate le rôle crucial qui lui incombe. Là encore, les émotions profanes cristallisées déclenchent le salut. Tenju a témoigné qu'elle avait pris conscience de l'impermanence de la vie et s'en est remis à Amida. La pratique poétique est élevée au rang d'ascèse du cœur. La jeune enfant sera guidée, et l'errance devient progression vers la rédemption. Cette incise poétique témoigne là encore de la persistance de genres littéraires anciens. Le poème est le pivot de cette scène, le livret s' inscrit au contraire dans la longue histoire de la littérature poétique du Japon ancien.

Le troisième tableau présente de nouveaux personnages. Par un procédé d'analepse (retour en arrière), le drame du mal incurable dont souffre le jeune Matsuwaka est narré aux spectateurs. Le temps n'est pas linéaire, un récit s'invite dans le récit, enrichissant encore la mosaïque textuelle.

Le quatrième tableau noue l'intrigue. Un devin vend la recette du remède qui pourra guérir le pauvre souffrant et après de vaines recherches, Tenju se révèle être la perle rare. Celle-ci consent à mourir pour soulager Matsuwaka. La thématique bascule du pitoyable à la grandeur du sacrifice accepté. Pathétique, la belle enfant fait don d'elle-même pour le salut de ses parents. Et elle prend soin de cacher sa résolution, pour ne pas affliger son jeune frère, qu'elle recommande à ses protecteurs.

«Vous tous qui m'écoutez, sachez que ces larmes ne viennent pas de ce que je pleure sur ma propre vie. Jamais je n'en ai voulu au destin. Cette vie de rosée, je la voudrais dédiée au salut de mes parents, elle n'est que vaine poussière. Regardez le triste sort de mon jeune frère. Comme je vous l'ai raconté, depuis que nous vivons orphelins de père et de mère, il était tout pour moi. Nous avons parcouru ensemble les montagnes, nous sommes ensemble descendus dans les plaines, m'ouvrant le chemin. Si je disparais, qu'adviendra-t-il de lui, qui prendra soin de lui, ah quelle désolation... » Dit-elle en mouillant sa manche de pleurs. 
Le cinquième tableau est en adéquation avec les canons du sekkyō. La scène de séparation est le clou du spectacle. Au passage le plus émouvant, l'aînée qui s'est retirée dans le temple la veille de l'immolation tranquillise son cadet par un pieux mensonge et, dans la solitude de la nuit, tente de calmer son anxiété. Elle lui caresse tendrement les cheveux alors qu'il s'est endormi après avoir prié Amida.

$\ll \ldots$ ah tes cheveux noir de jais, moi qui les nouais cinq fois par jour, pas un jour n'a passé que je les aie coiffés au moins trois fois. Dès demain, qui te tiendra ce rôle de sœur, n'y aura-t-il plus personne pour te considérer comme son frère ? Même pas trois, ne serait-ce qu'une fois, est-ce donc impossible, pauvre de nous... »

Au sixième tableau, la scène du sacrifice précède celle de la double surprise : l'enfant n'est pas morte, un miracle a eu lieu. La pièce se termine par la perspective des noces de la douce Tenju et du jeune Matsuwaka guéri. Un joyeux maelstrom entraîne l'audience vers la fin du spectacle se terminant sur ces mots :

Aux abords du pays de Bishari dans la vallée de l'Indus, est vénérée la célèbre triade d'Amida munewari, de jadis et à aujourd'hui sans changement aucun, cette piété filiale est un exemple qu'il n'est pas donné de voir si souvent, et il n'y avait pas un homme qui n'en soit pas ému.

Les textes précédents et même contemporains de cette pièce, comme l'histoire de la Demoiselle jōruri, étaient des textes littéraires antérieurs portés directement à la scène ${ }^{27}$. Les maladresses de style de notre Amida trahiraient plutôt une activité de réécriture visant à remodeler le texte pour le rendre plus compatible avec les exigences de la représentation scénique. La récitante, qui n'était pas une lettrée, aurait recomposé et travaillé ce livret.

Car l'apport essentiel de la représentation par la troupe Saruhachi-za repose sur l'ancienneté de la version jouée. Les traductions, analyses et commentaires proposés par C. J. Dunn ou Sakaguchi ne se basent pas sur ce qui a dû être le

27. C'est la thèse défendue par TsunODa Ichirō 角田一郎, Ningyō-geki no seiritsu ni kansuru kenkyū 人形劇の成立に関する研究 (Recherches sur la formation du théâtre de marionnettes), Osaka, Asahiya shoten 旭屋書店, 1963. 


\section{CIPANGO}

112 Cahiers d'études japonaises n²1

livret de 1614, mais sur des versions ultérieures, encore plus remaniées. La version établie en retranscription par Watanabe Hachitayū 渡部八太夫 (récitant) et Nishihashi Hachirobee 西橋八郎兵衛 ${ }^{28}$ daterait des ères Keichō 慶長 ou Genna 元和, soit entre 1596 et 1624 . La représentation nous permet de remonter encore en arrière et d'imaginer au mieux ce qui a été effectivement le point de départ du théâtre de poupées « moderne ».

Une analyse comparative des différentes versions permet d'isoler leurs caractéristiques.

\section{Un art de la scène en mutation, un découpage des scènes de plus en plus innovant}

Traditionnellement, la continuité du récit donne sa cohérence à l'ensemble. Si les coupures sont nécessaires au rythme de la représentation et à la progression de la narration, les personnages assurent la continuité de l'action d'une scène à l'autre. La pause n'est qu'une respiration et le drame reprend avec les mêmes protagonistes, comme un feuilleton qui se poursuit. La scène suivante débute toujours sur le même tableau, avec les mêmes personnages que la scène précédente, et l'action peut continuer. Or, dans les versions ultérieures et contrairement aux conventions de l'époque et du sekkyō notamment, certains personnages ne réapparaissent plus après l'entracte et les transitions entre les tableaux ne sont pas assurées textuellement et visuellement. De plus, certaines coupures ne paraissent pas conventionnelles. À la classique respiration dans le récit est préféré un découpage par action, chacune segmentée dans un espace narratif et scénique propre. Chaque tableau finit par acquérir ainsi une indépendance qui distingue cette pièce par la nouveauté de son écriture et la modernité de sa scénographie. Le fil du récit n’impose plus le découpage des scènes. La pièce apparaît comme un montage de tableaux autonomes.

28. Retranscription du 13 octobre 2011 à partir du texte disponible dans Kokubungaku kenkyū shiryōkan zōhō 国文学研究資料館蔵報 (Publications de l'Institut National de Littérature japonaise), $\mathrm{n}^{\circ}$ 52, Tōkyō, mai 2010, http://www.nijl.ac.jp/pages/ articles/200712/, en édition typographiée dite ancienne (kokatsujiban古活字版). 
Le procédé est notable dès l'ouverture du deuxième tableau : dans les versions de 1630, 1651 et 1660, plus aucun des protagonistes du premier tableau n'est présent, la scène s'ouvre sur les nouveaux premiers rôles que sont les deux enfants.

\begin{tabular}{|c|c|}
\hline Texte de 1596-1624 & Texte de 1651 \\
\hline $\begin{array}{l}\text { Fin du tableau } 1 \\
\text { «[Aux démons qui demandent à } \\
\text { Bouddha s'ils doivent épargner les } \\
\text { enfants,] Bouddha suggère, “Sauvez } \\
\text { cette fratrie!”» } \\
\text { 釈尊聞こし召して「この吕弟をば } \\
\text { 助けおけ」と御諚なり } \\
\text { Et dans la mise en scène de la } \\
\text { troupe Saruhachi-za, Tenju et } \\
\text { Teirei apparaissent vivants, prêts à } \\
\text { commencer leur long périple. }\end{array}$ & $\begin{array}{l}\text { Fin du tableau } 1 \\
\text { Les démons sont en train de torturer } \\
\text { les parents, Bouddha intervient et } \\
\text { leur interdit de tuer les enfants. Les } \\
\text { démons acquiescent et rentrent en } \\
\text { Enfer sans les tuer. } \\
\text { "Comment pourrait-on décrire la } \\
\text { fin affreuse qui fut celle de Kanshi } \\
\text { Byōe?» } \\
\text { かのかんし兵衛が最期の体、哀れ } \\
\text { ともなかなか申ばかりなりけり }\end{array}$ \\
\hline $\begin{array}{l}\text { Début du tableau } 2 \\
\text { «Pitoyable situation que celle de la } \\
\text { fratrie ainsi délaissée, Tenju et Teirei, } \\
\text { leur sort était bien misérable. » } \\
\text { 物の哀れを留めしは、後に残り天 } \\
\text { 寿ていれい兑にて諸事の衰れを } \\
\text { 留たり } \\
\text { Dans la mise en scène de } \\
\text { Saruhachi-za, le rideau souvre sur les } \\
\text { deux enfants dans la même position } \\
\text { qu’au tableau précédent. }\end{array}$ & $\begin{array}{l}\text { Début du tableau } 2 \\
\text { "Bien ensuite, pitoyable situation que } \\
\text { celle des enfants, la sœur aînée et son } \\
\text { cadet, leur sort était bien misérable. » } \\
\text { 扔ても其の後 物の哀れを留めた } \\
\text { は、姉弟の子供にて 物の哀れを } \\
\text { 留たり } \\
\text { Ici les enfants sont les nouveaux } \\
\text { personnages du nouveau tableau. }\end{array}$ \\
\hline
\end{tabular}

Dans le livret ancien, la prégnance des formes stylistiques anciennes est remarquable. Les tournures telles que tote et oba sont utilisées. Dans les versions ultérieures, on relèvera l'usage répété de la formule d'usage mōsu bakari (wa) nakari keri (il n'y a pas de mots pour qualifier cette scène [dramatique]). Mais surtout, le découpage avec suivi des personnages d'un tableau à l'autre a été abandonné. 


\section{CIPANGO}

114 Cahiers d'études japonaises n² 21

Prenons encore un exemple du début du quatrième tableau qui tranche tant dans la version décrite par Tsunoda. Dans le texte le plus ancien, le troisième tableau s'achève sur les silhouettes des enfants Tenju et Teirei qui, contrairement au spectateur, ne savent rien de la maladie du petit Matsuwaka. Ils suivent fidèlement les indications données en songe par Amida et se rendent chez le seigneur Daiman pour se vendre.

\begin{tabular}{|c|c|}
\hline Texte ancien : & Textes postérieurs : \\
\hline $\begin{array}{l}\text { Fin du } 3^{e} \text { tableau } \\
\text { «Alors qu'ils ne connaissaient que } \\
\text { des déboires et sans se douter de rien, } \\
\text { Tenju et son frère Teirei se rendirent } \\
\text { chez le seigneur Daiman afin de se } \\
\text { vendre. C’était d'une tristesse infinie! » } \\
\text { Љかなわざるところへ 天寿 } \\
\text { ていれい兄弟は これをば夢にも } \\
\text { 知らずして我が身売らんとて大ま } \\
\text { ん長者へ尋ね行きしは 諸事の哀 } \\
\text { れと聞こえけり* } \\
\text { Dans la mise en scène de } \\
\text { Saruhachi-za, un panneau a été dressé } \\
\text { au milieu de la scène annonçant que } \\
\text { lon recherche une jeune fille de telle } \\
\text { naissance. Aucune ne convenant, } \\
\text { toutes repartent. Le décor change. } \\
\text { S’avancent alors, arrivant du côté } \\
\text { jardin, Tenju et Teirei cherchant la } \\
\text { demeure du seigneur Daiman. }\end{array}$ & $\begin{array}{l}\text { Fin du } 3^{\mathrm{e}} \text { tableau, texte de } \mathbf{1 6 7 0} \\
\text { Au } 3^{\mathrm{e}} \text { tableau surgit un nouveau } \\
\text { personnage Gendabyōe, qui } \\
\text { voudrait marier sa fille au fils du } \\
\text { seigneur Daiman. Ce dernier refuse, } \\
\text { Gendabyōe prend alors conseil } \\
\text { auprès de Kagetsu Jirō, le chef de ses } \\
\text { guerriers, qui lui suggère l'offensive. } \\
\text { Mais la bataille tourne court, Kagetsu } \\
\text { est fait prisonnier, il est décapité après } \\
\text { avoir maudit Daiman. Sa tête s'envole, } \\
\text { la langue convulsionnée. } \\
\text { «Quoiqu'il en soit, le sort de Kagetsu } \\
\text { no Jirō était si terrible que les mots } \\
\text { manquent pour en parler.» } \\
\text { とにもかくにもかの花月の次郎が } \\
\text { 有様 をそろしきともなかなか申 } \\
\text { ばかりはなかりけり }\end{array}$ \\
\hline
\end{tabular}

\footnotetext{
* Page 16 du livret de travail de la troupe Saruhachi-za.
} 


\section{Début du $4^{\mathrm{e}}$ tableau}

«Alors, les gens de Daiman les regardent, la demoiselle est si belle, et son cadet a tant de maintien, ils pensent qu'il ne peut s'agir d'êtres anodins et sans même prendre la peine d'en avertir immédiatement le seigneur Daiman, ils les font d'abord entrer, leur proposant de séjourner quelque temps."

さても長者の身内の人々が 此の 兄弟を見るよりもあらいつくし の姫君や 若君の有様もただ世 の常の人にて無しなにさま長者 に申さずともまずまず留め置か ぬとて

Dans la mise en scène de Saruhachi-za, Tenju et Teirei sont sur scène. Sortent des coulisses les gens de Daiman qui, sétant étonnés de la prestance des jeunes enfants, font venir des plateaux chargés de bonne chair pour qu'ils puissent se restaurer, ainsi qu'un jeu de plateau pour divertir Teirei.

\section{Début du $4^{\mathrm{e}}$ tableau}

Texte de 1651 (montage de répliques précédentes)

Le tableau souvre sur Tenju et Teirei sapprochant de la demeure de Daiman, conformément aux instructions d'Amida. "Et par la suite, là encore, voici les pitoyables enfants, quel désarroi pitoyable, déjà l'aube blanchit, l'aînée se rapproche de son frère : "Dis-moi...”" さても其後こ々に又物の哀をと どめしは 姉弟の人々にて 物の 哀をとどめたり 既にその夜も明 けければ姉は弟を近づけて「い かに申さん...」

\section{Texte de 1660}

«Pas une seule demoiselle nétait de même naissance et toutes s'en retournèrent chez elles. "

ついに同じ相性の姫は一人も更に なし 皆々我が家へ帰られけり

\section{Texte de 1670}

«Ainsi donc, le seigneur Daiman avait gagné la bataille, mais son fils unique, le jeune Matsuwaka, souffrait maintenant d'un mal étrange, il était alité, agonisant. »

其ののち 大まん長者には 戦に は勝ち給えどもただ一人の松若 殿 不思議の病をひきうけて 万 時(万死)の床に臥したまう

Les troisième et quatrième tableaux s'inscrivent donc, dans le livret du début du XVII ${ }^{\mathrm{e}}$ siècle, dans la continuité de l'action. Les enfants qui se dirigeaient vers la demeure de Daiman y sont parvenus. 
Dans les textes postérieurs, la fin du troisième tableau connaît de grandes variations. Dans la version intermédiaire de 1651, le troisième tableau s'achève sur la tentative de trouver une jeune fille ayant exactement la même date de naissance que Matsuwaka, mais aucune prétendante ne convient. La linéarité du temps est effacée, car les protagonistes ne réapparaissent pas. Les premières lignes du quatrième tableau se singularisent d'ailleurs par la juxtaposition des premières stances des trois premiers tableaux précédents, et la référence intratextuelle est très inhabituelle pour l'époque. Ici la seule liaison est un montage textuel, une mosaïque de précédentes répliques apposées.

Dans la version la plus tardive, donnée à Edo en 1671 par Tenma Hachitayū 天 満八太夫, se trouve même insérée une scène supplémentaire expliquant l'origine du mal de l'enfant. Le petit Matsuwaka est en fait victime d'un maléfice lancé par un ennemi de la famille qui voulait se venger de son père, Daiman. Le fil temporel est coupé par un retour en arrière et une parenthèse vient couper l'unité d'action, au milieu de la pièce.

Au fil des livrets successifs, on imagine les récitants s'engager sur la voie d'une nouvelle écriture, élaborant une construction innovante du jeu scénique où la chorégraphie des marionnettes prendrait peu à peu le pas sur le continuum narratif. La mimesis l'emporte sur la diégèse jusqu'alors garant de la cohésion de la pièce. Le découpage en tableaux finis dicte désormais la mesure. La pièce s'éloigne ainsi de la tradition médiévale de la fluidité temporelle et du récit sériel. Elle inaugure un art assumé du montage, les scènes pouvant être conçues comme indépendantes les unes des autres, simplement apposées au sein d'une même histoire. Cette nouveauté, relevée par Tsunoda Ichirō 角田一郎 (dont nous avons présenté les thèses ci-dessus) et que retrace également Sakaguchi Hiroyuki 坂口弘之 dans Jöruri no sekai, est notable à partir du livret de 1651.

Notons que, si le texte ancien déroge une fois à la règle avec un passage très brutal du quatrième au cinquième tableau, la cause en serait moins une innovation dans l'écriture et le choix d'un nouvel agencement des scènes, qu'un problème de préservation de l'œuvre qui nous serait parvenue amputée d'une page. C'est en tout cas l'opinion du professeur émérite de Waseda, Torigoe Bunzō 鳥越文蔵, qui s'était entretenu avec nous après avoir assisté à l'une de nos répétitions.

Insistons donc sur le fait que cette nouveauté du découpage scénique n'est pas à mettre au crédit du rédacteur qui, à la fin du XVI $^{\mathrm{e}}$ et au début du XVII ${ }^{\mathrm{e}}$ siècle, a 
composé cette pièce qui a eu l'heur de plaire à un empereur alors plutôt accoutumé à d'autres spectacles. Elle correspond plutôt à des évolutions ultérieures. Si l'on prend la pièce d'Amida comme jalon des évolutions du genre, la révolution dans l'écriture théâtrale semble pouvoir être située après 1625 voire dans la deuxième moitié du XVII ${ }^{e}$ siècle.

\section{Un travail de réécriture au fil du siècle, l'importance des dialogues}

En un demi-siècle, l'écriture et le découpage ont changé. Les archaïsmes stylistiques venus du sekkyō se sont estompés. La pièce a été restructurée sans souci des conventions littéraires précédentes. Désormais, les coupures correspondent aux changements de scène et elles s'adaptent aux entrées et aux sorties des personnages. L'action des marionnettes régit le texte. Les personnages prennent même parfois le pas sur le chanteur et se chargent de la narration des parties les plus rocambolesques. La lecture comparée des deux livrets montre de notables évolutions dans l'écriture.

Prenons encore l'exemple du premier tableau : dans la première version, seules quatre tirades étaient insérées dans la masse de la narration. Ultérieurement, ces tirades sont non seulement développées en dialogues entre les personnages, mais de plus, des pans entiers de narration sont transformés en répliques. Avec quatorze tirades, on compte trois fois plus de parties dialoguées. Les marionnettes qui ne faisaient qu'illustrer le récit deviennent les porte-parole de l'action des protagonistes. Le texte est de moins en moins un paysage littéraire soutenant la pièce, il émane désormais des marionnettes et de leur interaction.

Par ailleurs, l'action est moins centrée sur l'Inde lointaine, et les comparaisons entre l'Inde, la Chine et le Japon se voient estompées sinon effacées. L'allusion à la traversée de la rivière Kikusui à la fin du deuxième tableau, et donc du voyage des enfants à travers la Chine, disparaît. L'espace du récit est recentré.

On constate d'autre part des modifications altérant le message bouddhique de la première pièce. Les sites sont changés, le Bouddha n'est plus sur le pic sacré des Aigles sur lequel le Bouddha historique donna son enseignement (en particulier le Sûtra du Lotus), mais sur le mont Dandaloka (Dandoku en japonais), massif montagneux du nord de l'Inde où, renonçant au monde profane, il s'adonna aux exercices ascétiques les plus sévères. Or, ces deux sites correspondent à deux 
différents cycles d'enseignement. Préférer le premier cycle au deuxième, c'est opter pour les seuls sûtras reconnus authentiques par toutes les branches du bouddhisme et préférer les sermons des quatre vérités plutôt que le Sûtra du Coeur (Shingyō), c'est enfin marquer un discret retour aux fondamentaux, un appel au renoncement. Par ailleurs, dans le livret ancien, juste avant le sacrifice de l'enfant, les sûtras sont juste évoqués et Tenju fait seulement défiler devant elle les pages des prières, tandis que dans le livret postérieur ils sont lus et vocalisés. On constate parallèlement une transformation de la vision du Bouddha, qui paraît moins impitoyable dans la version plus récente ${ }^{29}$. La scène du miracle est, elle, évacuée du livret de 1651, alors que, dans la première version, le spectateur se voyait conter une pluie de fleurs et l'envol d'un mystérieux nuage violet après qu'on eut arraché le foie de Tenju ${ }^{30}$. La piété l'emporte sur la notion de sacrifice.

\section{Une statue historique au cour de l'intrigue, le changement d'effigie}

Ce qui constitue le cœur même de la pièce, et détermine son titre, est la statue bouddhique sauvant Tenju. Or, celle-ci subit un traitement radicalement différent selon les époques. Dans la version donnée en 1614, la statue est désignée sous le nom d'Ikkō sanzon amida nyorai 一光三尊阿弥陀如来. Or cette appellation s'applique à une composition bien particulière, où Amida Nyorai 阿弥陀如来 et ses deux parèdres, Kannon Bosatsu 観音菩薩 et Seishi Bosatsu 勢至菩薩, se tiennent ensemble dans une seule et même mandorle ou halo de lumière (kōhai 光背). Les statues de ce type se retrouvent surtout dans le nord-est du Japon et suivent le modèle de l'une des plus anciennes statues bouddhiques du Japon, enchâssée dans le très célèbre temple Zenkōji 善光寺 de Nagano. On sait que

29. Le Bouddha intervient par exemple pour calmer les foudres des démons et sauver les enfants.

30. Le seigneur Daiman ne trouve pas le corps de la fillette sur les lieux du sacrifice, mais découvre plus tard, en se rendant au temple, à la fois Tenju endormie auprès de son frère et la statue ensanglantée. 
celle-ci connut une vogue extraordinaire au Xvi ${ }^{\mathrm{e}}$ siècle $^{31}$. C'est dans ce contexte que fut créée Amida no munewari, et l'on peut penser qu'elle fait allusion à cette statue dont le souvenir en était encore vif dans les mémoires. Comme nous le détaillions plus haut, les pièces de type sekkyō sont nombreuses à avoir pour rôle de rappeler aux fidèles l'histoire et la vertu salvifique d'un objet de culte (statue de Bouddha pour Amida no munewari, momie pour la pièce Kōchi hōin godenki 弘知法印御伝記, un Jizō dans Sanshō day ū, une source miraculeuse pour Oguri Hangan, pour n'en citer que quelques-uns ${ }^{32}$ ). La pièce conjugue ainsi motifs édifiants du bouddhisme, scénographie plaisante et innovante, ainsi qu'allusions sans doute assez explicites pour les contemporains aux pérégrinations d'une statue fabuleuse alors objet des rumeurs. Morale, divertissement et clin d'œil, les ingrédients du succès étaient réunis. Si on prête à Chikamatsu Monzaemon l'invention de la pièce anecdotique, entièrement tirée d'un fait divers, on pourrait souligner que c'est sans doute son adéquation à un événement de son temps qui a contribué au succès du premier Amida no munewari. Pour les contemporains de la première pièce, le sujet n'était pas simplement un prêche moralisateur mais aussi le traitement inédit d'un sujet dans le vent.

Dans les livrets ultérieurs, la référence au Ikkō sanzon disparaît. La statue n'est plus représentée que par une effigie d'Amida seul, sans référence aux deux bodhisattvas l'accompagnant. La scène perd son inscription événementielle, et plonge vers un message bouddhique plus convenu.

31. Longtemps installée au Zenkōji, la triade fut emportée par le seigneur de guerre Takeda Shingen (1521-1573), avec les moines du temple, jusque dans la province de Kai (l'actuel département de Yamanashi) où il lui fit construire un nouveau temple. Déplacée au Honnōji 本能寺 dans la province de Gifu par le fils aîné d'Oda Nobunaga (15341582), Oda Nobutada (1557-1582), elle fut ensuite installée par Toyotomi Hideyoshi (1536-1598) à Kyōto au temple Hōkōji 方広寺, dont le chantier est d'ailleurs perturbé par le tremblement de terre de 1596. La statue retrouva le chemin du Zenkōji en 1598, après 40 ans d'absence et Hideyoshi mourut le lendemain du départ de la triade pour Nagano (ZENKōJi JIMUKYOKU 善光寺事務局編 [dir.], Yokuwakaru zenkōji mairi 上< わかる善光寺参り [Bien comprendre et visiter le temple Zenkōji], Tōkyō, Shinkōsha 新晃社, 2008, p. 35).

32. Chloé Viatte, « "La Vie du Saint Moine Kōchi” : l'aventure de la reconstitution historique d'une pièce de marionnettes de 1685 », Ebisu, n 45, 2011, p. 119-134. 
120 Cahiers d'études japonaises n²1

Conventions théâtrales, scénographie, écriture, et, d'une certaine manière, nature du message bouddhique, Amida no munewari permet ainsi de découvrir de grandes évolutions ayant bousculé la scène japonaise en moins d'un demi-siècle. Le premier livret révèle encore la marque des pièces édifiantes médiévales du $s e k k y \bar{o}$. Le texte déroule le récit comme un flot qui avance régulièrement, vague après vague. Ce récit prend vie sur scène grâce à des marionnettes encore frustes, manipulées chacune par un seul marionnettiste qui œuvre à couvert, laissant la marionnette seule dans la lumière. Et c'est sans doute ce style nouveau de représentation qui a frappé les spectateurs et élargi sa renommée. Au long de sa traversée du siècle, la pièce d'Amida dévoile une écriture qui se libère et qui s'adapte. Elle transfigure le livret pour lui faire prendre pied dans son époque, une période riche d'innovations techniques pendant laquelle les artisans du théâtre de marionnettes enrichissent leur scène et cultivent leurs effets.

Il était important de donner à voir ce qu'avait été effectivement le texte de la pièce louée par ses contemporains, de lui rendre justice sans lui prêter a posteriori des traits qu'elle ne portait pas encore. C'est la mission que s'est donnée la troupe de Saruhachi-za, qui a redonné vie à la version la plus ancienne et trop méconnue de la pièce.

\section{Donner à voir Amida no munewari au $\mathbf{X X I}^{\mathrm{e}}$ siècle}

L'enjeu pour la troupe de Saruhachi-za - où l'auteur de ces lignes est marionnettiste depuis 2009 - fut de donner à voir cette pièce à nouveau, après plusieurs siècles. Comment rendre compte des différents visages d'Amida no munewari et évoquer les mutations scénographiques ayant marqué le livret ?

En partant du principe que la plasticité formelle de la pièce est en soi remarquable, que la montée des effets scéniques est un trait crucial de l'époque et que la pièce est un témoin de cette mutation, Nishihashi Hachirobee 西橋八郎兵衛 a souhaité proposer, sur le texte le plus ancien, une mise en scène très théâtralisée susceptible de suggérer la richesse des innovations du siècle.

Torigoe Bunzō 鳥越文蔵 de l'université de Waseda - qui avait confié à la troupe le livret inédit de la pièce Echigo no kuni, Kashiwazaki - Kōchi-hōin godenki 越後國 柏崎一弘知法印御伝記 (Province d'Echigo, cité de Kashiwazaki : la vie du Saint Moine Kōchi) qu'il avait découvert dans les archives du British 
Museum de Londres et qui avait pu être rejoué pour la première fois depuis plus de trois cents ans en $2010^{33}$ - avait dès 2009 confié à Nishihashi son envie de voir jouée la pièce d'Amida no munewari qui n'avait pas connu la scène depuis des siècles malgré la place importante qu'elle tient dans l'histoire des arts de la scène au Japon.

\section{Le miracle d'une représentation anniversaire}

En octobre 2011, le livret était établi par Nishihashi et Watanabe. Le 13 avril 2012, la première représentation put avoir lieu. À cette date, les préparatifs pour le premier acte n'étaient pas encore achevés. À cinq minutes du lever du rideau, nous étions encore à finir le décor et seuls les deuxième et troisième actes furent donnés.

La pièce fut par la suite donnée dans son intégralité en octobre 2012 à Jōetsu dans un des plus anciens cinémas du Japon, à Takada (département de Niigata) en collaboration et avec le soutien financier de l'université de Jōetsu, en septembre 2013 dans la ville de Toyota (département d'Aichi) dans le cadre du $13^{\mathrm{e}}$ festival de Story Telling de Toyota, puis en octobre 2014 dans la ville de Niigata (département de Niigata) avec le soutien financier de l'université de Niigata. Dans un souci pédagogique et afin de faire connaître au mieux cette œuvre, la représentation d'octobre 2014 donnée dans la salle de la Maison de la culture du département de Niigata 新潟県民会館 était gratuite, l'ensemble des frais ayant été pris en charge par l'université de Niigata et le centre de recherches de la faculté de Lettres chargé de la coordination culturelle au niveau local 人文学部附置地域 文化連携セン夕一。

Mais, ce 13 avril 2012 correspondait à une date très importante pour le récit d'Amida, et le récitant Watanabe Hachitayū 渡部八太夫 souhaitait à tout prix que la pièce puisse être donnée ce jour anniversaire. Amida no munewari tourne en effet autour de la symbolique date de naissance de Matsuwaka et de Tenju, à l'heure du dragon, le jour du dragon, du mois du dragon, de l'année de dragon-eau. Or, l'année du dragon-eau du calendrier zodiacal chinois ne se répète que tous les 60 ans, 1612 et 2012 sont justement des années sous ce signe zodiacal.

33. Ibid. 


\section{CIPANGO}

122 Cahiers d'études japonaises n²1

Le mois du dragon tombait en 2012 en avril. C'est l'envie de redonner vie à la pièce le jour même de cet anniversaire qui a motivé toute la troupe à accélérer préparatifs et répétitions. Le spectacle fut particulièrement éprouvant, n'étant pas encore parfaitement abouti et donné gratuitement dans l'enceinte du temple Tōkōji, qui accueille la troupe et lui fournit un lieu de répétition depuis 2011.

Le récitant composa l'accompagnement au shamisen et prit le parti de réorganiser la pièce en trois actes, gedan (premier et deuxième tableaux), chüdan (troisième et quatrième tableaux) et jōdan (cinquième et sixième tableaux).

Les marionnettes des personnages principaux sont à hochement de tête (unazuki ningyō) comme il est de tradition dans l'art de la poupée bun.ya ningyō de l'île de Sado. Les manipulateurs, un par marionnette, sont dissimulés aux regards par leur kimono noir (kuroko 黑子) et leur capuche (zukin 頭巾). En effet, Nishihashi a été formé au bunraku d'Osaka. Par souci de confort visuel pour les spectateurs, les marionnettistes de notre troupe ont adopté ce costume de scène. Lors de ce $\mathrm{XVII}^{\mathrm{e}}$ siècle si intéressant du point de vue de l'histoire de la manipulation en effet, les marionnettes avaient progressivement acquis la mobilité de la main droite, grâce à l'artifice de la main du manipulateur directement glissée dans la manche de la marionnette, des mouvements de tête, grâce à la mise au point du mécanisme (karakuri) du hochement de la tête (unazuki 領き) ou encore la mobilité des doigts de la main (tezuma 手妻). Certaines ont même été dotées de jambes, qui peu à peu ont nécessité l'appoint de manipulateurs supplémentaires. Edo Magoshirō est notamment resté célèbre dans les annales pour avoir expérimenté dès 1680-1690 des poupées avec des jambes manipulées par trois personnes, ce qui nécessita un nouveau genre de scènes. Les plateaux ayant grandi, les représentations ont fini par être données dans des enclos réservés, qui deviendront des lieux de théâtre. La performance commençait peu à peu de dicter sa logique au texte rédigé.

\section{Problèmes scénographiques}

Nous avons évoqué plus haut le premier tableau. Le décor une fois planté, les trésors merveilleux sont présentés et le seigneur Kanshi Byōe かんし兵衛 déclare vouloir se détourner du bouddhisme, provoquant l'ire du Bouddha, des batailles de démons, le supplice des impies et le massacre de villageois par centaines. À 
l'été 2011, Nishihashi, soucieux de l'enjeu et des difficultés concernant la représentation de ce tableau foisonnant, avait provisoirement opté pour la projection à l'aide d'une « lanterne magique » ou de «projections colorées d'images » de type utsushi-e 写し絵, afin de pallier les rapides changements de lieux ou les scènes de batailles opposant les monstres aux épées magiques. En effet, le récitant Watanabe Hachitayū 渡部八太夫 est non seulement l'héritier d'une longue tradition du sekkyō dite Tama-sekkyō qui a été préservée dans le Kantō aux alentours de Tōkyō, mais il est également membre de l'Association du utsushi-e et avait déjà dans son répertoire des versions d'Oguri hangan chanté avec accompagnement de projections lumineuses.

Ce médium aurait permis de pallier les écueils de ce premier passage de la pièce. Pourtant, il aurait été anachronique puisque la première attestation de ce type d'ombre chinoise semble dater du tout début du XIX ${ }^{\mathrm{e}}$ siècle, en 1803. Tsunoda Ichirō 角田一郎 suggère dans ses pages de penser la scène avec des marionnettes n'incarnant pas le texte, mais le dansant, en utilisant une gestuelle de danse traditionnelle de type buyo 舞踊. Dans son ouvrage, le chercheur utilise le terme technique de « narration dansée », mai-katari 舞語り. Le fil de l'action est illustré par le mouvement, sans que les péripéties ne soient actualisées en détail sur scène. Cette technique permet, en s'en remettant à l'imaginaire du spectateur, d'évoquer plus simplement l'action. La marionnette endosse là un rôle nouveau lui permettant d'affirmer sa préséance. Danseuse, elle devient le double $\mathrm{du}$ conteur, sans plus se cantonner à être une projection du texte. Le bun.ya de Hakusan, dans le département d'Ishikawa, témoigne encore peut-être de cette catégorie. Il existe deux troupes au style différent dans cette région, et cet art de la marionnette, appelé dekumawashi でくまわし, consiste justement à faire danser et virevolter (mawashi) en rythme et sans souci de gestuelle réaliste de petites poupées «deku » emmanchées sur un bâton manipulé.

La piste de la projection par lanterne magique a été délaissée au profit d'un autre artefact, Nishihashi a proposé d'ouvrir le spectacle avec une narration « figurée ». Le rideau s'ouvre donc sur une marionnette de moine expliquant les péripéties de l'action par une série d'images peintes sur un rouleau se déroulant au centre de la scène. Elles représentent les moments clés du récit de ce premier tableau. Ce procédé s'inspire de la pédagogie ancienne des moines qui vulgarisaient le message bouddhique auprès d'un public peu lettré, voire illettré, en commentant 


\section{CIPANGO}

124 Cahiers d'études japonaises n²1

des images (etoki 絵解き). Ce recours scénographique plonge habilement la pièce dans l'histoire des origines du théâtre de poupées et du sekkyō-bushi, dont on a déjà dit le souci prosélyte de transmettre aux masses le message bouddhique. L'etoki utilisait le pouvoir des images dans un but pédagogique afin de transmettre et d'expliquer le sens religieux des peintures bouddhiques. Avec cette scénographie d'Amida, le spectateur moderne se retrouve dans la position du petit peuple à qui est contée une histoire édifiante dont les signes clés sont figurés et donnés à voir au centre de la scène par l'entremise d'une marionnette. Ceux-ci constituent une trame à partir de laquelle les passages les plus spectaculaires sont « incarnés » sur scène.

Citons par exemple la scène des deux épées que le texte suggère tourbillonnantes et fendant l'espace (悪魔を払う剣が出でて天地を四方へ切つて回 れば). La marionnette récitante, en moine, raconte donc les combats, les montre en image et son récit est doublé d'une représentation scénique. De petites épées fixées sur de longues tiges sont agitées par des marionnettistes de façon à les faire tourbillonner en l'air. Des accessoires manipulés à couvert sont intégrés à la narration, et le combat des 98000 démons est juste suggéré par le dessin doublant en contrepoint le chant.

L'interpénétration du texte et de l'image, du graphique et du récit, du figuré et de la narration, dont on trouve tant d'exemples singuliers dans l'art japonais, trouve ici toute sa force. La pratique de l'image racontée, «légendée » sous les yeux de l'assistance, a joué un rôle décisif dès la période de Muromachi (13331576) dans la vie des temples, l'orientation de l'histoire de l'art et la constitution d'arts de la scène. Dans Amida, le texte du premier tableau résistait à la personnification, le trépidant microcosme fut alors partiellement figuré pour être mieux déchiffré, la marionnette et la performance étant à tout point de vue les médiatrices de l'histoire. Médium qui donne son unité à la pièce, puisque Nishihashi a choisi de faire intervenir à nouveau cette marionnette narratrice à la toute fin du spectacle, afin qu'elle en explicite le dénouement. En quelques lignes la fin de l'histoire est enlevée, le jeune Teirei prend la tonsure et les noces sont annoncées, ce récit trop bref résistait également à l'incarnation scénique directe. Le moine récitant ressurgit, referme la pièce et lui donne sa logique. 


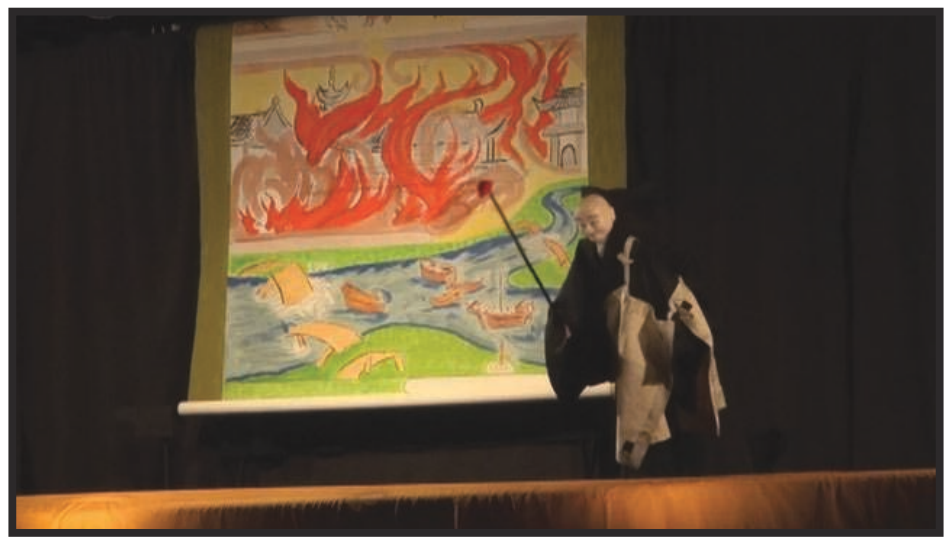

FIGURE 2.

Marionnette récitante, etoki du premier tableau. Spectacle de la troupe Saruhachi-za,

13 avril 2012.

Source : cliché de Watanabe Hachitayū

\section{Le travail de création}

La composition musicale précède la chorégraphie des marionnettes. Une fois la trame de la partie chantée aboutie, les marionnettistes improvisent sous l'œil du chef de troupe et les propositions les plus intéressantes sont retenues pour la mise en scène. Cependant, les mouvements ne sont pas strictement chorégraphiés, et si tant est qu'ils correspondent au jōruri et qu'ils tombent juste, l'interprète manipulateur garde toute latitude pour modifier son geste. Les représentations peuvent beaucoup varier d'un spectacle à l'autre.

L'interprétation de certains seconds rôles surtout fait l'objet de discussions. Attardons-nous un peu sur le personnage du mage. Sur quel mode aborder ce personnage au rang social élevé, certes crucial dans le développement de l'intrigue puisque c'est lui qui comprend que c'est le foie d'une jeune fille particulière qui pourra seul sauver l'enfant malade, mais qui apparaît à la fois pédant et cupide ? Après plusieurs tentatives, il fut convenu de lui donner un aspect comique. Tel un Diafoirus d'un autre monde, il s'agitait en tous sens, étalant sa science des maux dans une glose pseudo-savante. Puis, réjoui de mettre la main sur la masse d'or 


\section{CIPANGO}

126 Cahiers d'études japonaises n²1

qui lui est offerte en remerciement de sa divination mortifere, il quitte les lieux. Tirer l'interprétation vers la caricature permettait de faire respirer l'auditoire à ce moment noir de l'histoire. Un côté burlesque qui n'aurait peut-être pas déplu au petit peuple spectateur du premier Amida. Pourtant, ces élucubrations ont dû paraître superfétatoires à ses contemporains mêmes, puisque dans les textes postérieurs ce passage fut radicalement réduit sinon coupé. La comparaison des différents livrets de L'Intendant Sanshō semble confirmer cette évolution des mœurs. En effet, là aussi, dans les versions anciennes, une divination de type Yi-King avec des tiges et trigrammes permet de confirmer au protagoniste que sa mère est encore de ce monde. Mais dans les livrets postérieurs, cet épisode est tout simplement abandonné, reléguant ce recours aux « mages » à des temps révolus n'ayant plus à occuper le devant de la scène. Les pratiques cultuelles changent et le théâtre garde la mémoire de ces évolutions.

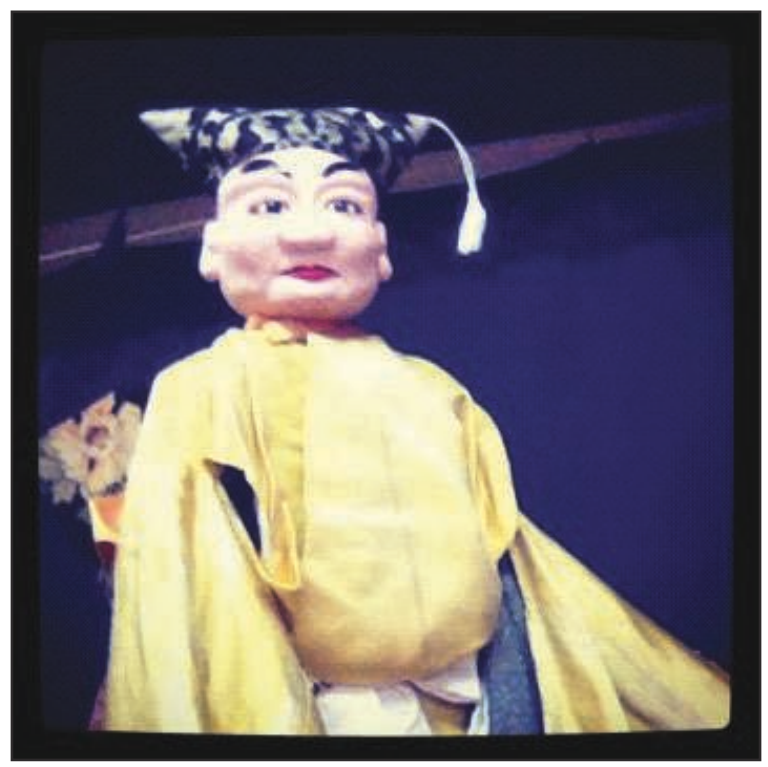

FIGURE 3.

Marionnette du mage Hakase. Spectacle de la troupe Saruhachi-za, 13 avril 2012. Source : cliché de Chloé Viatte 


\section{En guise de conclusion}

Nous avons voulu montrer l'intérêt de l'analyse de la pièce à succès d'Amida au poitrail déchiré, qui témoigne des évolutions foisonnantes ayant agité le théâtre de poupée en ce premier XVII ${ }^{\mathrm{e}}$ siècle. Elle marque l'émergence d'une nouvelle scène, qui a drainé dans son sillage l'établissement de changements stylistiques notables qui à leur tour ont permis la fondation d'un nouvel art de la scène, d'un nouveau genre théâtral. L'analyse diachronique des livrets a permis d'entrevoir les nouvelles pistes qui se sont ouvertes aux saltimbanques du XvII ${ }^{\mathrm{e}}$ siècle. D'un point de vue stylistique comme scénographique, la pièce a marqué une étape importante dans l'histoire du spectacle de marionnettes au Japon. La teneur très religieuse de la pièce mettant en lumière une effigie aujourd'hui méconnue d'Amida peut sembler très éloignée des préoccupations des spectateurs du XXI ${ }^{\mathrm{e}}$ siècle. Un spectacle ressuscitant l'ancêtre oublié du théâtre ancien de marionnettes aurait pu rebuter l'audience. Pourtant cet objet scénique rare a su attirer les spectateurs. Et en ces temps où les liens familiaux sont plus tenus que jadis, le sacrifice de soi et la piété filiale continuent de fasciner et émouvoir.

Jouer Amida no munewari aujourd'hui est l'occasion de remonter à la source du spectacle de marionnettes traditionnel et de montrer comment le théâtre de poupées réussit à s'émanciper des autres littératures. C'est aussi faire sentir aux spectateurs du $\mathrm{XXI}^{\mathrm{e}}$ siècle les transformations successives qui ont permis qu'émerge ensuite à Osaka la fleur du spectacle de marionnettes, les pièces de ce « nouveau jöruri » (shin-jōruri 新浄瑠璃), à qui le théâtre de Chikamatsu Monzaemon donnera ses lettres de noblesse. La troupe de Saruhachi-za s'efforce de redonner un souffle à des pièces oubliées qui peuvent encore résonner au cœur des Japonais modernes. Jouée après les catastrophes de mars 2011, la représentation était concomitante du choix du kanji kizuna 絆 (lien), alors symbole de l'année. Par-delà les siècles et malgré ces nombreux archaïsmes, émotions profanes et religieuses restent étroitement tissées et Amida au poitrail déchiré sait encore surprendre. Gageons que le style de chant élégiaque et rythmé du bun.ya a également contribué à prendre les auditeurs au cœur. Et comme le propre de la marionnette est aussi d'être le réceptacle des états d'âme des humains qui les regardent évoluer, chaque génération y projette l'arcen-ciel de sa sensibilité ; l'amour pour les siens y trouve son écho comme le revers peut-être du projet de foi inébranlable en Amida chantée dans les vers. 
CIPANGO

128 Cahiers d'études japonaises n² 1

\section{Bibliographie}

\section{Sites internet}

Watanabe Hachitayū 渡部八太夫 : http://blog.goo.ne.jp/wata8tayu.

Tokyo National Museum : http://www.tnm.jp/modules/rblog/index.php/1/ category/9?start $=5$ [blog 1089].

\section{Bibliographie indicative}

Dunn Charles James, The Early Japanese Puppet Drama, London, Luzac \& Company Ltd, 1966.

KANŌ Katsumi 加納克己, Nihon ayatsuriningyō-shi 日本操り人形史 (Histoire de la marionnette au Japon), Tōkyō, Yagi shoten 八木書店, 2007.

Kokubungaku kenkyū shiryōkan zōhō 国文学研究資料館蔵報 (Publications de l'Institut National de Littérature japonaise), no 52, Tōkyō, mai 2010, http:// www.nijl.ac.jp/pages/articles/200712/.

Keene Donald, Bunraku: The Art of the Japanese Puppet Theatre, Tōkyō, Kōdansha International Ltd, 1965.

MURoki Yatarō 室木弥太郎, Katarimono (mai, sekkyō, kojōruri) no kenkyū 語り 物（舞 説経 古浄瑠璃）の研究 (Études du récit [danse, sekkyō, jōruri ancien]), Tōkyō, Kazama shobō 風間書房, 1970.

NingYō BUTAI-SHI KENKYŪKAI 人形舞台史研究会 (dir.), Ningyō jōruri butai-shi 人形浄瑠璃舞台史 (Histoire de la mise en scène du théâtre de marionnettes), Tōkyō, Yagi shoten 八木書店, 1991.

Ortolani Benito, The Japanese Theatre: from Shamanistic Ritual to Contemporary Pluralism, Princeton, Princeton University Press, 1995. 
Pigeot Jacqueline, Michiyuki-bun, poétique de l'itinéraire dans la littérature du Japon ancien, Paris, Maisonneuve et Larose, 1982.

SAKAGUCHI Hiroyuki 阪口弘之編 (dir.), Jöruri no sekai 浄瑠璃の世界 (Le monde du jōruri), Kyōto, Sekai shisōsha 世界思想社, 1992.

Shinoda Jun.ichi 信多純一, SAKaguchi Hiroyuki 阪口弘之, Kojōruri sek$k y \bar{o}-s h \bar{u}$ 古浄瑠璃 説教集 (Jōruri ancien, recueil de pièces sekkyō), Tōkyō, Iwanami shoten 岩波書店, « Nihonkoten bungaku taikei 》日本古典文学 大系, $\mathrm{n}^{\circ}$ 90, 1999.

Sieffert René, Histoire de demoiselle Jōruri, Cergy, Publications orientalistes de France, « Tama », 1994.

ToKUdA Kazuo 徳田和夫, Ekatari to monogatari 絵語りと物語 (Décrire et écrire, de l'image au récit), Tōkyō, Heibonsha 平凡社, 1990.

Torigoe Bunzō 鳥越文蔵, Uchiyama Mikiko 内山美樹子, Watanabe Tamotsu 渡辺保 (dir.), Kabuki, bunraku - Jōruri no tanjō to kojōruri 歌舞伎 文楽－浄瑠璃の誕生と古浄瑠璃 (Kabuki, bunraku: naissance du jöruri et ancien jōruri), vol. 7, Tōkyō, Iwanami shoten 岩波書店, 1998.

TsunOda Ichirō 角田一郎, Ningyō-geki no seiritsu ni kansuru kenkyū 人形劇 の成立に関する研究 (Recherches sur la formation du théâtre de marionnettes), Osaka, Asahiya shoten 旭屋書店, 1963.

Viatte Chloé, « "La vie du Saint Moine Kōchi" : l'aventure de la reconstitution historique d'une pièce de marionnettes de $1685 \gg$, Ebisu, n 45, 2011, p. 119-134.

WaKaTsUKi Yasuharu 若月保治, Ningyōjōruri-shi kenkyū 人形浄瑠璃史研究 (Recherches sur l'histoire du ningyō jōruri), Tōkyō, Sakurai shoten 桜井書 店, 1943. 


\section{CIPANGO}

130 Cahiers d'études japonaises n² 21

Wakita Haruko 脇田晴子, Josei geinō no genryū - kugutsu, kusemai, shirabyōshi 女性芸能の源流－傀儡子 曲舞 白拍子 (Aux origines des arts traditionnels féminins : kugutsu, kusemai, shirabyōshi), Tōkyō, Kadokawa gakugei shuppan 角川学芸出版, 2001.

YASUDA Tokiko 安田登貴子, Kojōruri - tayū no juryō to sono jidai 古浄瑠璃一 太夫の受領とその時代 (Jöruri ancien : les titres honorifiques des chanteurs et leur temps), Tōkyō, Yagi shoten 八木書店, 1998.

ZENKŌJI JIMUKYOKU 善光寺事務局編 (dir.), Yokuwakaru zenkōji mairi よく わかる善光寺参り (Bien comprendre et visiter le temple Zenkōji), Tōkyō, Shinkōsha 新晃社, 2008.

Résumé : La plus ancienne pièce de marionnette jouée sur scène au Japon et dont nous ayons la trace s'intitule Amida no munewari. La représentation eut lieu en 1614 devant la cour impériale. À cette époque, l'art de la marionnette appelé ningyō jōruri ou jōruri ancien est une forme artistique en plein essor. Amida no munewari fut joué, repris et adapté durant tout le $\mathrm{XVII}^{\mathrm{e}}$ siècle et l'analyse de ses livrets successifs montre comment a évolué ce théâtre de poupée, qui donnera naissance aux pièces de Chikamatsu Monzaemon puis permettra l'émergence du bunraku. En 2012, la troupe Saruhachi-za a relevé le défi de monter cette pièce oubliée et qui pourtant se révèle être un chainon crucial dans l'histoire des arts de la scène japonais.

Mots-clés : Jōruri, sekkyō, Saruhachi-za, Amida no Munewari, marionnettes traditionnelles, arts de la scène

Abstract: Amida no Munewari is said to be the oldest puppet play to have been performed on stage in Japan, in 1614. At the beginning of the seventeenth century puppet theatre, known as ningyō jōruri or kojōruri, was blossoming. Meanwhile, Amida no Munewari was performed several times during the seventeenth century. The evolutions of its libretto reveal the progressive mutations of this performing art, which lead to the creation of Chikamatsu Monzaemon's plays, and later on, to the 
birth of bunraku. In 2012 the puppet troupe Saruhachi-za rose to the challenge of performing what is a forgotten play and a vital link in the history of Japanese performing arts.

Keywords: Jōruri, Sekkyō, Saruhachi-za, Amida no Munewari, Traditional Japanese Puppet Theatre, Performing Art

キーワード：人形浄瑠璃, 伝統芸能, 芸能興行, 猿八座, 阿弥陀胸割, 説経節 